\title{
Percutaneous Renal Biopsy
}

\author{
Louis-Philippe Laurin, Alain Bonnardeaux, \\ Michel Dubé and Martine Leblanc \\ University of Montreal \\ Canada
}

\section{Introduction}

Renal biopsy is an essential tool for the diagnosis of several renal diseases. The first renal biopsies were performed in 1923 as open surgical procedures (Gwyn, 1923). The percutaneous approach has been part of the clinical practice since 1951 (Iversen \& Brun, 1951). A few years later, a description of the procedure with the patient placed in a prone position was published (Kark \& Muehrcke, 1954). The new technique had a success rate of more than $90 \%$ and was not associated with major complications. Percutaneous ultrasoundguided renal biopsy is now considered as the standard method. It is a routine procedure that can be done with minimal discomfort to the patient. Here we review major topics related to this frequent and useful procedure in the field of nephrology.

\section{Indications}

Although indications for renal biopsy can sometimes be a matter of debate among nephrologists, common indications include: isolated hematuria, mild to moderate proteinuria, nephrotic syndrome, glomerulonephritis, acute renal failure, renal manifestations of systemic diseases and chronic renal failure (Table 1). There is also an important role for percutaneous kidney biopsy in kidney transplantation. Percutaneous kidney biopsy is not only reserved for the diagnosis of renal parenchymal diseases, but it may also have a role in the diagnosis of renal tumor as described below in this chapter.

Impacts of diagnosis made by kidney biopsy have to take into account considerations beyond therapeutic implications. A kidney disease diagnosis within the patient's records could have psychological and financial consequences (e.g. insurances), and can modify family planning decisions (e.g. hereditary renal diseases) (Korbet, 2002). Performing a percutaneous kidney biopsy therefore implies a good communication between the attending physician and his patient.

\section{Contraindications}

In 1988, the Health and Public Policy Committee of American College of Physicians (ACP) elaborated a list of contraindications to kidney biopsy (ACP, 1988). As described below, the relevance of this policy may be actually questioned upon recent technological developments resulting in a virtual absence of catastrophic complications in recent series (Waldo et al., 2009). 


\subsection{Absolute contraindications}

Several contraindications to renal biopsy have been described (Madaio, 1990). Absolute contraindications are generally recognized as uncontrolled bleeding diathesis, anatomic abnormalities, uncooperative behaviour and pregnancy (Table 1). Chronic renal disease associated with two small kidneys with cortical atrophy remains a contraindication to renal biopsy, since the bleeding risk is high, but can be considered relative if performed by a wellexperienced operator. Absence of an appropriate pathologic support makes no sense to perform a biopsy and should therefore be considered as a contraindication (Korbet, 2002). Single functioning kidney is not considered as an absolute contraindication anymore because of technical and real-time imaging improvements over the last decades. As stated in a report of nine cases of normal size solitary kidney biopsy, it can be performed with good outcomes in terms of bleeding and renal function (Mendelssohn \& Cole, 1995). In this series, the only complication reported was post-procedure gross hematuria in one patient. Histopathological diagnosis was made in eight of nine cases.

One can argue that an uncooperative patient is no longer an absolute contraindication in particular circumstances. Intensive care unit patients on mechanical ventilation appear to tolerate well bedside biopsy with appropriate administration of sedative agents (Conlon et al., 1995). The procedure is performed off ventilator with ventilation controlled with an ambu bag, permitting a perfect synchronization between respiratory movements and needle insertion, thereby minimizing risks of complications.

\subsection{Relative contraindications}

Relative contraindications consist in conditions that may be reversed, sometimes relatively easily; these include uncontrolled hypertension or hypotension, renal abscesses, pyelonephritis, hydronephrosis, marked obesity, severe anemia, previous technical failure, uremia, anatomic abnormalities of kidney such as large renal tumors, arterial aneurysm and cysts (Table 1) (Madaio, 1990). Correction of these medical conditions with antihypertensive medication, antibiotics or blood transfusions makes possible the biopsy to be carried out safely.

\section{Preparation}

First, the patient's past medical history information should be reviewed before the biopsy. Personal and family history of bleeding diathesis, and allergy to substances used during the procedure such as povidone-iodine should be evaluated. Second, a thorough physical examination should be undertaken to look for skin infection as well as anatomic anomalies (e.g. obesity) that could interfere with the procedure. An assessment of blood pressure control is also essential.

A pre-biopsy laboratory evaluation is also made routinely and includes complete biochemical profile, complete blood count and urinalysis. Baseline coagulation parameters, including platelet count, prothrombin time, partial thromboplastin time and fibrinogen, are usually documented before biopsy procedure. Bleeding time is also commonly analyzed prior to the biopsy, but its role to predict post-biopsy bleeding remains controversial; it will be discussed in detail later in this chapter. Stopping all the medications that could disrupt normal coagulation should normally prevent post-procedural bleeding. Antiplatelet agents and non-steroidal anti-inflammatory drugs have to be withdrawn prior to the procedure for at least seven days. Performing a renal biopsy in patients on anticoagulation therapy is 
always a medical challenge. Decision to stop the anticoagulants before the biopsy should be based on the patient's thromboembolism risks. If the decision is made to do the biopsy, an anticoagulation bridge with intravenous anticoagulation (e.g. heparin) is needed in most cases.

A good preparation is an essential step to minimize the risk of bleeding complications as well as to intervene promptly in case of an adverse event.

\begin{tabular}{l|l} 
Indications & Contraindications \\
\hline Isolated hematuria & Relative \\
Mild to moderate proteinuria & Uncontrolled hypertension \\
Nephrotic syndrome & Hypotension \\
Nephritic syndrome & Renal abscesses \\
Glomerulonephritis suspicion & Pyelonephritis \\
Renal manifestations of & Hydronephrosis \\
systemic diseases & Marked obesity \\
Acute renal failure & Severe anemia \\
Chronic renal failure & Uremia \\
Renal tumor in selected & Large renal tumors or cysts \\
patients & Solitary kidney \\
& Previous technical failure \\
& Atrophic kidney(s) \\
& Absolute \\
& Bleeding diathesis \\
& Anatomic abnormalities \\
& Uncooperative behavior \\
& Pregnancy
\end{tabular}

Table 1. Indications and contraindications of kidney biopsy

\section{Procedure}

As mentioned earlier, percutaneous renal biopsy under ultrasound guidance is now the gold standard method to obtain renal tissue for the diagnosis of renal diseases. It is generally considered superior to other techniques because of its numerous advantages: it allows continuous visualization of both kidney and needle, can be done regardless of the renal function, avoids exposure to radiation, permits procedure to be performed at bedside and avoids the administration of nephrotoxic contrast media (Korbet, 2002). Several other biopsy techniques exist, such as laparoscopic, computed tomography (CT)-guided and transjugular renal biopsy. Here, we will focus mainly on ultrasound-guided techniques.

An adequate tissue sample (Figure 1) permitting an accurate diagnosis of a glomerular disease with light microscopy usually contains 8 to 10 glomeruli. It must include juxtamedullary glomeruli due to their preferential involvement in focal segmental glomerulosclerosis. In these focal lesions, at least 25 glomeruli may be required to have greater than $95 \%$ chance of finding evidence of such renal injury (Fogo, 2003).

In 1988, the American College of Physicians (ACP) stated the minimal requirements (Table 2) that a nephrology fellow must acquire to perform percutaneous renal biopsy safely (ACP, 1988). It is interesting to note that in a recent survey among 133 nephrology trainees, $75.3 \%$ 
of them reported that they had little or no training, or some training but not enough to feel competent in doing renal biopsy independently (Berns, 2010).

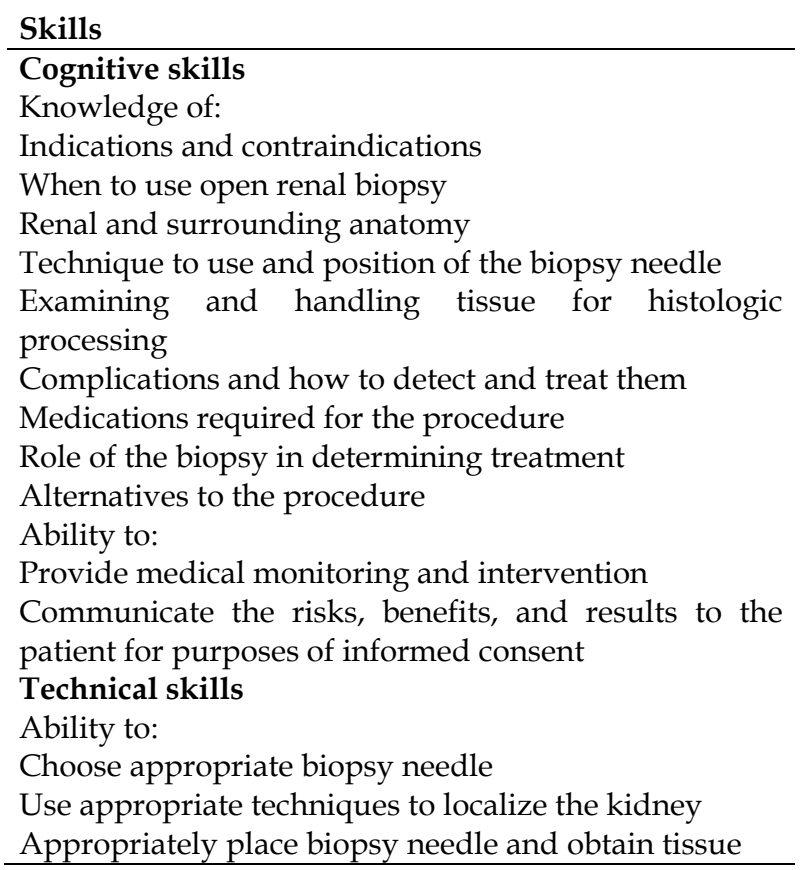

Table 2. Skills related to percutaneous renal biopsy (from ACP, 1988)

The patient should provide an informed consent before the procedure. No oral intake is usually permitted after midnight on the day of the procedure, except for a light meal if the procedure is planned late in the morning or early in the afternoon. A well-trained nephrologist or radiologist at the radiology department, or at bedside if needed, usually performs the procedure. An intravenous access is placed to insure adequate hydration. Vital signs have to be monitored throughout the procedure.

Kidney biopsies are usually performed with the patient in prone position, after the skin is properly disinfected and draped. This position provides the most rational approach to a retroperitoneal organ. It also brings the kidney closer to the posterior abdominal wall. Local anesthesia is usually carried out with lidocaine. Tissue biopsies are acquired from the lower pole of the kidney, next to the renal capsule, with the left kidney usually preferred for ergonomic reasons. The operator must be aware that subcapsular cortical samples have overrepresentation of sclerosis related to hypertension, aging and non-specific scarring (Fogo, 2003). Samples are obtained when the patient is holding his breath. One or two needle passes are routinely performed.

Another approach, commonly used to perform liver biopsy, is the transjugular renal biopsy. This technique is usually performed in academic centers by well-trained interventional physicians (nephrologists or radiologists) and should be reserved for high-risk patients with contraindications to percutaneous renal biopsy such as liver disease, bleeding diathesis and obesity. The main disadvantage of this technique is lower diagnostic yield, mainly because 
medulla needs to be traversed first before reaching the renal cortex. A recent retrospective study showed a good safety and efficacy of transjugular renal biopsy in 23 high-risk patients (Sarabu et al., 2010). An adequate tissue for histopathological diagnosis was obtained in $87 \%$ of patients. Three patients $(13 \%)$ experienced bleeding requiring blood transfusion. Neither deaths nor embolization/nephrectomy were reported.

A supine antero-lateral position (SALP) for percutaneous biopsy has been suggested recently (Gesualdo et al., 2008). It can be an interesting and useful alternative to the prone position for obese patients. This technique is also less invasive than a transjugular biopsy, and certainly provides a better diagnostic yield due to a direct access to the distal cortex. High-risk patients with a BMI $>30$ and/or respiratory difficulty underwent a SALP biopsy and were compared with low-risk (BMI $\leq 30$ and/or no respiratory difficulty) patients receiving ultrasound-guided renal biopsy in either the prone position or SALP, for a total of 110 patients. There were a significantly better comfort compliance and less breathing difficulties for SALP patients. Post-procedure bleeding complications were minor in all three groups. The authors concluded that SALP may therefore be considered seriously for patients who otherwise would have been submitted to more invasive procedure.

\subsection{Optimal depth}

Pasquariello and colleagues (Pasquariello et al., 2007) published a novel approach to calculate the optimal depth needed to decrease significantly hemorrhagic complications, as well as tissue sample inadequacy. All 126 percutaneous native kidney biopsies, using a 14gauge automated biopsy gun under sonographic guidance, were performed with optimal depth previously calculated. Adequacy rate of specimens for diagnosis and complication rate were compared with retrospective data obtained for 123 biopsies. Incidence of bleeding complications was significantly reduced using the theoretical calculation of optimal depth, together with an adequate sampling permitting an accurate diagnostic evaluation from renal tissue. Depth where pushing the trigger was calculated by a mathematical formula defined below (1).

$$
\text { Optimal depth }=\text { BW } / \mathrm{H}-0.5
$$

BW represents the body weight expressed in hectograms and $\mathrm{H}$ the height expressed in centimeters.

\subsection{Real-time versus blind ultrasound}

Biopsy procedure can be performed under real-time or blind ultrasound-guided technique. Real-time method implies continuous visualization of the kidney for exact localization of the biopsy site (Figure 2). Blind method requires a sonographic localization of the kidney only before needle insertion. A proper needle placement is thereafter assessed by appropriate tissue resistance and observation of the respiratory excursion of the needle. A study by Maya and colleagues (Maya et al., 2007) showed that real-time ultrasound-guided technique provided a superior yield of kidney tissue and resulted in fewer bleeding complications. This retrospective study of 129 patients showed a higher mean number of glomeruli per biopsy in the sonographic-guided group compared to the blind biopsy group (18 \pm 9 versus $11 \pm 9)$, and fewer large hematomas requiring intervention ( $0 \%$ versus $11 \%)$. 


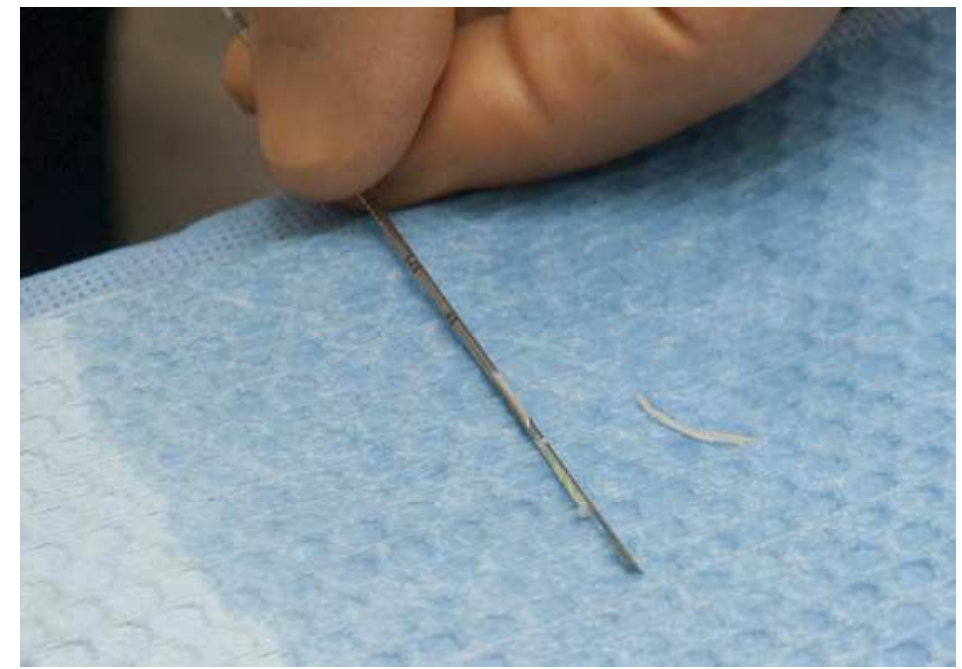

Fig. 1. Adequate tissue sampling

\subsection{Outpatient observation versus hospitalization}

The low occurrence rate of bleeding complications with percutaneous kidney biopsies performed under real-time ultrasound led to elective procedures in an outpatient setting using standardized protocols. Overnight hospitalization would not be therefore needed, reducing the overall cost of elective renal biopsies.

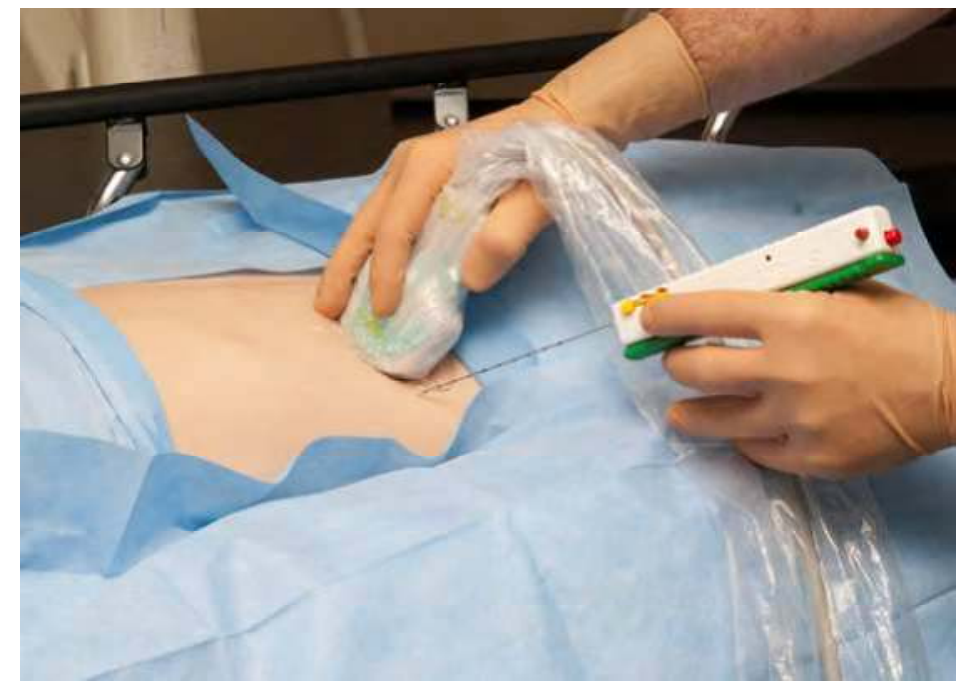

Fig. 2. Real-time ultrasound biopsy in prone position

A recent study by Maya and Allon (Maya \& Allon, 2009) confirmed the safety and effectiveness of such an approach. During a 20-month period, 100 patients underwent a 
percutaneous renal biopsy under real-time ultrasound guidance with a 16-gauge springloaded biopsy gun. A majority of patients (91\%) required only one or two needle passes, reflecting the technical advantage of the real-time ultrasound guidance. A color Doppler ultrasound was performed immediately after the procedure to exclude active bleeding. In this series, no patient experienced serious complications related to the biopsy. Only four patients were hospitalized because of an $>4 \%$ decrease in their hematocrit. Neither blood transfusion nor selective embolization was needed for these patients. Nonetheless, one can argue that such an approach should be reserved for highly selected patients who do not need urgent renal biopsy in the setting of acute kidney injury or bleeding disorders.

Common sense should therefore prevail regarding the decision to hospitalize or not a patient after biopsy. It is mainly an institution-based decision. At our hospital, we prefer to hospitalize all patients overnight after the biopsy.

\section{Needle}

Several types of needles have been used during medical history to perform percutaneous renal biopsy. In 1951, Iversen and Brun (Iversen \& Brun, 1951) described a percutaneous native kidney biopsy technique using an aspiration needle. Later, Kark and Muehrcke (Kark \& Muehrcke, 1954) published a technique whereby cutting needles were employed, such as the Franklin-Vim-Silverman and the Tru-Cut (Baxter, Deerfield, IL) needles. The automated biopsy-gun (Figure 3) became popular in the nineties based on its potential benefits in reducing bleeding complications, for shorter actual time the needle resides in the kidney, and the fact that it requires less dexterity by the operator (Madaio, 1990). A randomized prospective trial comparing the two methods showed adequate tissue sampling, but the extent of bleeding was more severe in the free-hand biopsy group (D. Kim et al., 1998).

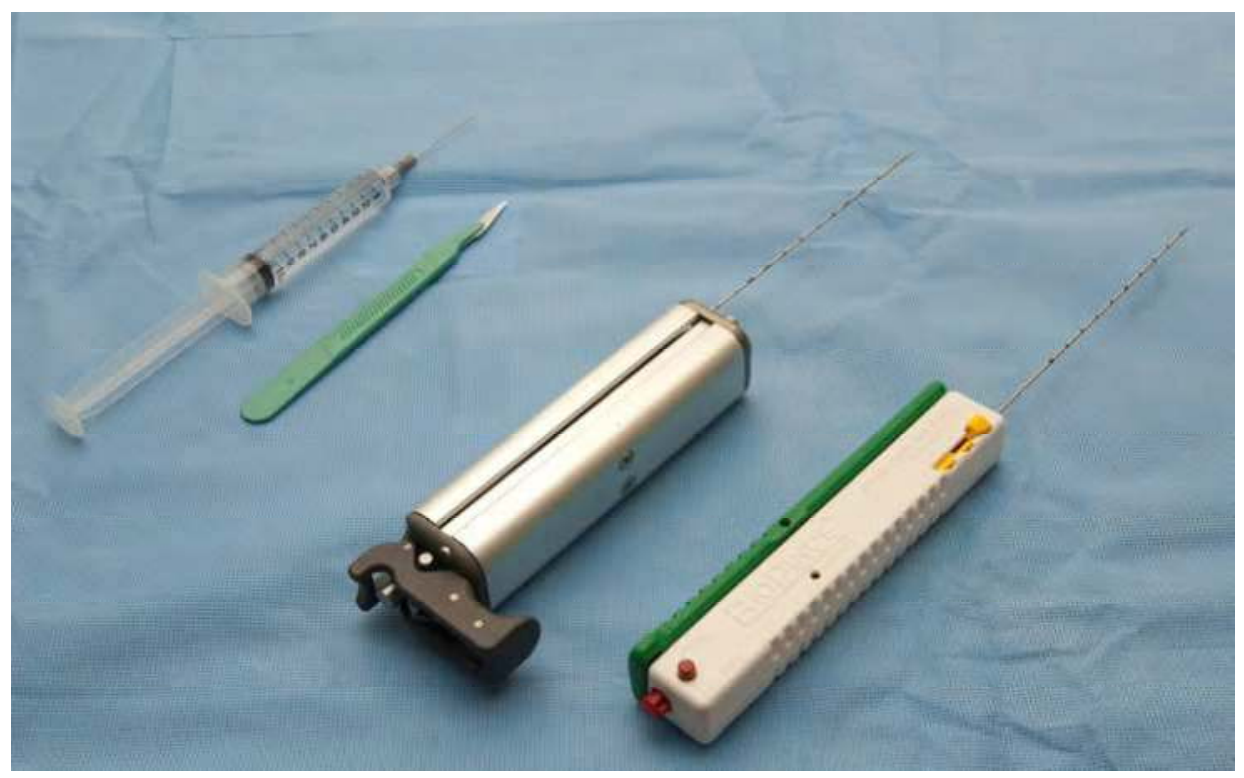

Fig. 3. Automated biopsy-gun 
A number of different needle sizes are available for percutaneous biopsy techniques, ranging from 14 to 18 gauge $(G)$. Needle gauge has a huge impact on the sample obtained. Eighteen- or 19-G needles are often unable to give a good specimen, and provide inadequate representation of vessels. In past years, there were concerns in the literature regarding bleeding risk with the use of larger needles. However, recent data (Tung et al., 1992; Song \& Cronan, 1998; Nicholson et al., 2000; Manno et al., 2004) refuted such beliefs by showing that larger gauge needles provided better adequacy in tissue sampling and were not associated with higher complication rates. More specifically, a study (Nicholson et al., 2000) comparing 14, 16, and 18-G needles in renal transplants demonstrated an improved diagnostic value with increased needle size and no significant difference in macroscopic hematuria between the three groups. Nevertheless, the use of $14-\mathrm{G}$ needle may create more pain. Overall, utilization of $16 \mathrm{G}$ needle appears to be the best compromise between patient comfort and histopathological diagnostic yield.

\section{Complications}

Complications associated with percutaneous renal biopsy can be categorized as minor (gross hematuria and silent hematoma), major (hematoma requiring transfusion and/or embolization) or catastrophic (loss of functional mass and death) (Mendelssohn \& Cole, 1995). Percutaneous renal biopsies using aspiration technique were associated with severe complications, mainly hemorrhage, with mortality rates of nearly $0.07 \%$ in large series reported in the fifties (Schwarz et al., 2005).

\begin{tabular}{l|l} 
Complications & Rate of occurrence \\
\hline $\begin{array}{l}\text { Minor } \\
\text { Gross hematuria } \\
\text { Silent hematoma }\end{array}$ & $\begin{array}{l}0 \text { to } 6 \% \text { (Maya et al. 2009) } \\
33.3 \% \text { (Manno et al. 2004) }\end{array}$ \\
\hline $\begin{array}{l}\text { Major } \\
\text { Hematoma requiring transfusion } \\
\text { and/or embolization }\end{array}$ & $1.2 \%$ (Manno et al. 2004) \\
\hline $\begin{array}{l}\text { Catastrophic } \\
\text { Loss of functional mass } \\
\text { Death }\end{array}$ & $\begin{array}{l}6 \text { per } 10000 \text { (Schow et al. 1992) } \\
7 \text { per } 10000 \text { (Schow et al. 1992) }\end{array}$ \\
Close to zero (Mendelssohn et al. \\
$1995)$
\end{tabular}

Table 3. Complications of percutaneous renal biopsy

Two main technical advances have resulted in safer procedures: the ultrasound guidance and the automated core biopsy system (automated biopsy-gun). Rates of serious complications were as low as $<1 \%$ in recent series, with an overall risk of kidney function loss of 6 per 10000 and a mortality risk of 7 per 10000 (Schow et al., 1992). Nonetheless, complications more commonly reported are transient gross hematuria and hematoma with a frequency ranging between $0 \%$ to $6 \%$ (Maya \& Allon, 2009). A literature review published in 1995 supports the opinion that the risk of catastrophic complications using the actual biopsy methods is close to zero (Mendelssohn \& Cole, 1995). These differences observed in 
complication rates may result from patient selection, biopsy technique, needle gauge, operator experience and number of needle passes.

Despite the fact that percutaneous biopsy can be now considered as a procedure with almost no catastrophic complications if it is performed with standard techniques, it is always associated with minor complications that the attending physician must be aware of. There is obviously a transient damage to the collecting system and to the structures surrounding the kidney. This generates bleeding, creating symptoms such as hematuria and a drop in hemoglobin level (see below). Microscopic hematuria is normally seen in all patients who undergo a kidney biopsy (Altebarmakian et al., 1981), but is generally clinically insignificant and revolves spontaneously within 24 to 48 hours. On the other hand, macroscopic hematuria is seen less frequently, complicating up to 5 to $10 \%$ of patients (Marwah \& Korbet, 1996). It is also generally clinically insignificant and self resolving in 48 hours. It can be severe, resulting in a significant loss of blood. It should also raise concerns for a concomitant hematoma or arteriovenous fistula, requiring further investigation and monitoring.

Normally, a fall in hemoglobin level is observed after a percutaneous renal biopsy, with a decrease $\geq 1 \mathrm{~g} / \mathrm{dL}$ reported in $20.8 \%$ of patients in a recent Japanese study (Ishikawa et al., 2009). A perinephric hematoma of more than $2 \mathrm{~cm}$ was associated with a significantly greater decrease in $\mathrm{Hg}$ level in this study. This drop is usually caused by several factors including local bleeding at the biopsy site (e.g. hematoma, hematuria), hemodilution secondary to hydration with intravenous fluids, recumbency and stimulation of anti-diuretic hormone secretion by pain; and it is not a good predictor of post-biopsy outcome.

Subcapsular perinephric hematoma is certainly more common than previously noted in older retrospective studies where post-procedure sonography was not routinely performed. A recent series of patient showed that hematoma was seen in $33.3 \%$ of patients, with a mean surface area of $289.6 \mathrm{~mm}^{2}$ (Manno et al., 2004). These hematomas were clinically silent in $90.4 \%$ of subjects, with $2.5 \%$ complaining of lumbar pain. It appears that there was no association between post-biopsy bleeding and the surface area of the hematoma. Another series reported hematomas in more than $86 \%$ of cases, and older studies using computerized tomography (CT) scanning also showed an incidence of $90 \%$, depending on the timing of the evaluation. Furthermore, the clinician must be aware of an extremely rare complication that may be associated with a perinephric hematoma: the laceration of a lumbar artery passing over the lower pole of the kidney (K.T. Kim et al., 1991).

Arteriovenous fistulas are also clinically silent complications of percutaneous renal biopsy. Angiography-based imaging studies reported an incidence of about $10 \%$. The majority (over $90 \%$ ) resolved spontaneously a year later, requiring no invasive procedure. They rarely become a symptomatic aneurysm that causes high output cardiac failure, hypertension, hematuria and renal failure (by arterial steal). Due to the gravity of the potential complications related to arteriovenous fistulas, they should be monitored with Doppler ultrasound every 3 to 6 months (Korbet et al., 2002).

In summary, there are numerous complications related to percutaneous kidney biopsy ranging from silent hematomas to uncontrolled bleeding with hemorrhagic shock. Clinicians must therefore be aware of these adverse events and investigate rapidly patients who present signs of clinical deterioration. This argues for an overnight observation of the patient after the procedure, with adequate monitoring of his vital signs, degree of hematuria and abdominal pain. 


\subsection{Predictors of bleeding complications}

Determining the predictors of bleeding complications related to percutaneous kidney biopsy has always been a matter of debate in the literature over the last decades, despite the fact that this procedure is routinely and frequently performed worldwide. There are scant prospective data regarding which baseline conditions (e.g. bleeding time, age) can affect significantly the outcomes. A recent Italian prospective study tried to answer this important question (Manno et al., 2004). The authors analyzed baseline characteristics and outcomes of 471 consecutive native kidney percutaneous ultrasound-guided biopsies. Univariate and multivariate analysis of predictors of post-biopsy bleeding complications demonstrated a strong association between post-procedure bleeding and female gender, higher baseline partial thromboplastin time and age, as bleeding tends to occur less in older patients. Surprisingly, no association was made between bleeding time and post-biopsy bleeding. Patients with complications had exactly the same bleeding time than patients without any complications, but all patients with abnormal bleeding time received 8-D-arginine vasopressin (DDAVP), showing afterwards a normalization of their bleeding time prior to biopsy. Only 11 patients had increased bleeding time prior to biopsy, two with moderate von Willebrand factor deficiency and nine with moderate renal failure. Moreover, there was also no impact of the histologic diagnosis on the occurrence of post-biopsy bleeding.

\begin{tabular}{|c|c|}
\hline Predictors of post-biopsy bleeding & $\begin{array}{l}\text { Factors not associated with post- } \\
\text { biopsy bleeding }\end{array}$ \\
\hline $\begin{array}{l}\text { Manno et al. } 2004 \\
\text { Younger age } \\
\text { Female gender } \\
\text { Elevated partial thromboplastin time } \\
\text { Ishikawa et al. } 2009 \\
\text { Perirenal hematoma } \geq 2.0 \mathrm{~cm} \\
\text { assessed immediately after biopsy } \\
\text { PT-INR } \geq 1 \\
\text { Mean blood pressure } \geq 105 \mathrm{mmHg} \\
\text { Steroid use }\end{array}$ & $\begin{array}{l}\text { Manno et al. } 2004 \\
\text { Blood pressure } \\
\text { Body weight } \\
\text { Serum creatinine } \\
\text { Proteinuria } \\
\text { Needle gauge } \\
\text { Waldo et al. } 2009 \\
\text { Absence of hematoma } 1 \text { h post- } \\
\text { biopsy } \\
\text { Ishikawa et al. } 2009 \\
\text { Age } \\
\text { Creatinine } \geq 2.0 \mathrm{mg} / \mathrm{dL}\end{array}$ \\
\hline
\end{tabular}

Table 4. Predictors of post-biopsy bleeding

A recent retrospective study of 317 patients tried to find predictors of overt bleeding after renal biopsy (Ishikawa et al., 2009). More than $86 \%$ of patient presented a perirenal hematoma after biopsy, a majority with a diameter of less than $2 \mathrm{~cm}$. A hematoma $\geq 2 \mathrm{~cm}$ was associated with a greater decrease in hemoglobin levels. The authors determined by multivariate analysis the clinical predictors of bleeding ( $\mathrm{Hb}$ decrease $\geq 1.0 \mathrm{~g} / \mathrm{dL}$ ). Perirenal hematoma, prothrombin time-international normalized ratio (PT-INR), mean blood pressure and steroid use were found to be related to overt bleeding (Table 4). Of these factors, perirenal hematoma $\geq 2 \mathrm{~cm}$ immediately after the biopsy was the strongest predictor, with a risk of severe anemia increased to about eight times. Post-biopsy ultrasound may therefore be a useful tool to discriminate patients with the highest risk of bleeding complications. However, a recent investigation studying the presence of a hematoma 1 hour post-biopsy as a predictor of major complications was not conclusive (Waldo et al., 2009). The absence of 
hematoma was predictive of an uncomplicated post-biopsy evolution, with a negative predictive value of $95 \%$.

\subsection{Role of bleeding time in predicting bleeding complications}

Utilization of bleeding time prior to the renal biopsy procedure remains controversial. Bleeding time is used frequently by nephrologists before biopsy, mainly for historical reasons, as a predictor of bleeding in spite of no clear evidence supporting its role.

On the one hand, a widespread consensus among hematologists supports the fact that it is not a useful predictor of the risk of hemorrhage after a surgical procedure, especially if there is absence of a clinical history of bleeding disorder. Bleeding time could indeed be altered in several conditions including technique variability related to the operator, drugs (e.g. betablockers, antibiotics) and various clinical states such as liver disorders and diabetes mellitus (Mattix \& Singh, 1999). No study linking the bleeding risk of performing kidney biopsies with abnormal bleeding time has been published. Furthermore, an article describing the position of the College of American Pathologists and the American Society of Clinical Pathologists concluded that bleeding time can be a test useful for testing the response to DDAVP in uremic patients, but it is not a predictor of the bleeding risk in these patients (Peterson et al., 1998).

On the other hand, recent data has shown that prolongation of the bleeding time is not without risk. It was found that the risk of post-biopsy hematoma increased by $21 \%$ for each minute of bleeding time prolongation, conferring a two times greater risk of bleeding in patients in which such a rise was seen (Stratta et al., 2007). More recent data demonstrated the same increased risk of major bleeding complications in patients with prolonged bleeding time (Waldo et al., 2009). Moreover, a prospective study of liver biopsies performed without correcting the bleeding time prior to the procedure showed five times higher bleeding complications (Boberg et al., 1999).

DDAVP seems to enhance the release of von Willebrand factor from endothelial cells into plasma. It also increases release of factor VII and adenosine triphosphate by platelets, as well as the uptake of serotonin. Studies have shown a normalization of the bleeding time by DDAVP infusion. Administration of this drug systematically regardless of bleeding time values appears to be cost-ineffective, considering that approximately $80 \%$ of patients had normal bleeding times, and it could be related to serious side effects such as hypertension and hyponatremia (Mattix \& Singh, 1999; Korbet, 2002). However, a recent randomized controlled trial showed a significant advantage of a systematic DDAVP administration in patients without a significant renal impairment (Manno et al., 2011).

\section{Role of percutaneous biopsy in renal tumors}

Percutaneous renal biopsies also have a smaller role in the management of renal tumors in adults. Indeed, surgical resection permits a clear pathological diagnosis, as well as generally curing the patient from his/her malignancy. This is based on the fact that carcinomas represent $90 \%$ of all renal solid masses in adults when tumor size is greater than $40 \mathrm{~mm}$ on imaging studies (Lebret et al., 2007).

Nevertheless, partial or total nephrectomies can be spared for renal masses less than $40 \mathrm{~mm}$ in size. A study from a French group showed that renal biopsy prior to surgical resection of a renal mass should be reserved for patients in whom imaging was not able to make an accurate diagnosis (Lebret et al., 2007). It mainly consisted of equivocal lesions that lacked 
one or more radiological criteria for malignant lesions, or were less than $40 \mathrm{~mm}$. In this single institution series of 432 patients, 119 percutaneous biopsies were performed in 101 patients. A diagnosis of benign lesions was made in $20 \%$ biopsies together with 9 malignant lesions not requiring surgery (lymphoma and metastasis) (Table 5). Thus, $30.4 \%$ of patients were not candidates for nephrectomy.

Performing such technique in patients with renal cancer is not without risk. In fact, biopsy tract seeding has been reported in $0.01 \%$ of cases in a large series (Smith, 1991, as cited in Lebret et al., 2007). This can be prevented by using coaxial system. In the series described above, no cancer seeding was reported, making percutaneous biopsy a safe procedure in the hands of well-experienced interventional physicians.

\begin{tabular}{ll} 
Histological findings & \% of lesions \\
\hline Malignant & \\
Renal cell carcinoma & 59 \\
Transitional cell carcinoma & 48 \\
Metastasis & 3 \\
Lymphoma & 7 \\
Benign & $<1$ \\
Oncocytoma & 20 \\
Angiomyolipoma & 13 \\
Renal abscess/xanthogranulomatosus & 3 \\
pyelonephritis & 4 \\
Inconclusive & 21 \\
Normal parenchyma & 10 \\
Necrotic tissue & $<1$ \\
Inflammatory tissue & 10
\end{tabular}

Table 5. Histological findings in renal masses (from Lebret et al. 2007)

Despite the fact that surgical resection remains the standard approach for patients with renal tumors, percutaneous biopsy could also be an alternative for particular cases. Fine needle aspiration of a renal mass can also be reserved for patients who would not be able to tolerate surgery, mainly elderly patients, and those with comorbid conditions.

\section{Conclusion}

Ultrasound-guided percutaneous renal biopsy is a safe procedure with a central role in the diagnosis of parenchymal kidney diseases. Real-time ultrasonography and automated biopsy-gun are the major technical improvements permitting the procedure to be performed with safety and effectiveness. It is accomplished in a hospital setting by well-trained radiologist or nephrologist. With recent technical advances, bleeding complications are quite rare, allowing a shorter observation period (6 to 8 hours) after the procedure in highly selected elective patients.

Areas of uncertainty however still exist. Predictors of bleeding complications are difficult to define clearly. Age, female gender and elevated prothrombin time seem to correlate with an increased risk of post-biopsy bleeding. Ultrasound undertaken immediately after the biopsy procedure can be helpful to determine if the patient is at a risk of bleeding and should be observed for longer period. The role of bleeding time remains controversial to predict overt bleeding mainly due to the fact that no prospective data are available to guide the clinical practice. 
Randomized controlled trials would therefore be needed to evaluate certain important questions mainly related to post-procedure bleeding. As approximately 1 to 2 million bleeding time tests are performed annually, it would be interesting to clarify its usefulness as a predictor of post-biopsy bleeding.

\section{Acknowledgements}

We wish to thank the staff of the Hôpital Maisonneuve-Rosemont radiology department.

\section{References}

Altebarmakian, V. K. et al. (1981). Percutaneous kidney biopsies. Complications and their management. Urology, Vol. 18, No. 2, (August 1981), pp. 118-22, ISSN 0090-4295

American College of Physicians. (1988). Clinical competence in percutaneous renal biopsy. Health and Public Policy Committee. Ann Intern Med, Vol. 108, No. 2, (February 1988), pp. 301-3, ISSN 0003-4819

Berns, J. S. (2010). A survey-based evaluation of self-perceived competency after nephrology fellowship training. Clin J Am Soc Nephrol, Vol. 5, No. 3, (March 2010), pp. 490-6, ISSN 1555-905X

Boberg, K. M. et al. (1999). Is a prolonged bleeding time associated with an increased risk of hemorrhage after liver biopsy? Thromb Haemost, Vol. 81, No. 3, (March 1999), pp. 37881, ISSN 0340-6245

Conlon, P. J., Kovalik, E., \& Schwab, S. J. (1995) Percutaneous renal biopsy of ventilated intensive care unit patients. Clin Nephrol, Vol. 43, No. 5, (May 1995), pp. 309-11, ISSN 0301-0430

Fogo, A. B. (2003). Approach to renal biopsy. Am J Kidney Dis, Vol. 42, No. 4, (October 2003), pp. 826-36, ISSN 1523-6838

Gesualdo, L. et al. (2008). Percutaneous ultrasound-guided renal biopsy in supine anterolateral position: a new approach for obese and non-obese patients. Nephrol Dial Transplant, Vol. 23, No. 3, (March 2008), pp. 971-6, ISSN 1460-2385

Gwyn, N. B. (1923). Biopsies and the Completion of certain Surgical Procedures. Can Med Assoc J, Vol. 13, No. 11, (November 1923), pp. 820-3, ISSN 0008-4409

Ishikawa, E. et al. (2009). Ultrasonography as a predictor of overt bleeding after renal biopsy. Clin Exp Nephrol, Vol. 13, No. 4, (August 2009), pp. 325-31, ISSN 1437-7799

Iversen, P. \& Brun, C. (1951). Aspiration biopsy of the kidney. Am J Med, Vol. 11, No. 3, (September 1951), pp. 324-30, ISSN 0002-9343

Kark, R. M. \& Muehrcke, R. C. (1954). Biopsy of kidney in prone position. Lancet, Vol. 266, No. 6821, (May 1954), pp. 1047-9, ISSN 0140-6736

Kim, D. et al. (1998). A randomized, prospective, comparative study of manual and automated renal biopsies. Am J Kidney Dis, Vol. 32, No. 3, (September 1998), pp. 42631, ISSN 1523-6838

Kim, K. T. et al. (1991). Embolic control of lumbar artery hemorrhage complicating percutaneous renal biopsy with a 3-F coaxial catheter system: case report. Cardiovasc Intervent Radiol, Vol. 14, No. 3, (May-June 1991), pp. 175-8, ISSN 0174-1551

Korbet, S. M. (2002). Percutaneous renal biopsy. Semin Nephrol, Vol. 22, No. 3, (May 2002), pp. 254-67, ISSN 0270-9295

Lebret, T. et al. (2007). Percutaneous core biopsy for renal masses: indications, accuracy and results. J Urol, Vol. 178, No. 4, (October 2007), pp. 1184-8, ISSN 0022-5347

Madaio, M. P. (1990). Renal biopsy. Kidney Int, Vol. 38, No. 3, (September 1990), pp. 529-43,. ISSN 0085-2538 
Manno, C. et al. (2011). Desmopressin Acetate in Percutaneous Ultrasound-Guided Kidney Biopsy: A Randomized Controlled Trial. Am J Kidney Dis, Vol. 57, No. 6, (February 2011), pp.850-855, ISSN 0272-6386

Manno, C. et al. (2004). Predictors of bleeding complications in percutaneous ultrasound-guided renal biopsy. Kidney Int, Vol. 66, No. 4, (October 2004), pp. 1570-7, ISSN 0085-2538

Marwah, D. S. \& Korbet, S. M. (1996). Timing of complications in percutaneous renal biopsy: what is the optimal period of observation? Am J Kidney Dis, Vol. 28, No. 1, (July 1996), pp. 47-52, ISSN 0272-6386

Mattix, H. \& Singh, A. K. (1999). Is the bleeding time predictive of bleeding prior to a percutaneous renal biopsy? Curr Opin Nephrol Hypertens, (November 1999), Vol. 8, No. 6, pp. 715-8, ISSN 1062-4821

Maya, I. D. \& Allon, M. (2009). Percutaneous renal biopsy: outpatient observation without hospitalization is safe. Semin Dial, Vol. 22, No. 4, (July-August 2009), pp. 458-61, ISSN 1525-139X

Maya, I. D. et al. (2007). Percutaneous renal biopsy: comparison of blind and real-time ultrasound-guided technique. Semin Dial, Vol. 20, No. 4, (July-August 2007), pp. 3558, ISSN 0894-0959

Mendelssohn, D. C. \& Cole, E. H. (1995). Outcomes of percutaneous kidney biopsy, including those of solitary native kidneys. Am J Kidney Dis, Vol. 26, No. 4, (October 1995), pp. 580-5, ISSN 0272-6386

Nicholson, M. L. et al. (2000). A prospective randomized trial of three different sizes of corecutting needle for renal transplant biopsy. Kidney Int, Vol. 58, No. 1, (July 2000), pp. 390-5, ISSN 0085-2538

Pasquariello, A. et al. (2007). Theoretical calculation of optimal depth in the percutaneous native kidney biopsy to drastically reduce bleeding complications and sample inadequacy for histopathological diagnosis. Nephrol Dial Transplant, Vol. 22, No. 12, (December 2007), pp. 3516-20, ISSN 0931-0509

Peterson, P. et al. (1998). The preoperative bleeding time test lacks clinical benefit: College of American Pathologists' and American Society of Clinical Pathologists' position article. Arch Surg, Vol. 133, No. 2, (February 1998), pp. 134-9, ISSN 0004-0010

Sarabu, N. et al. (2010). Safety and Efficacy of Transjugular Renal Biopsy Performed by Interventional Nephrologists. Semin Dial, (December 2010), ISSN 1525-139X

Schow, D. A., Vinson, R. K., \& Morrisseau, P. M. (1992). Percutaneous renal biopsy of the solitary kidney: a contraindication? J Urol, Vol. 147, No. 5, (May 1992), pp. 1235-7, ISSN 0022-5347

Schwarz, A. et al. (2005). Safety and adequacy of renal transplant protocol biopsies. Am J Transplant, Vol. 5, No. 8, (August 2005), pp. 1992-6, ISSN 1600-6135

Song, J. H. \& Cronan, J. J. (1998). Percutaneous biopsy in diffuse renal disease: comparison of 18- and 14-gauge automated biopsy devices. J Vasc Interv Radiol, Vol. 9, No. 4, (JulyAugust 1998), pp. 651-5, ISSN 1051-0443

Stratta, P. et al. (2007). Risk management of renal biopsy: 1387 cases over 30 years in a single centre. Eur J Clin Invest, Vol. 37, No. 12, (December 2007), pp. 954-63, ISSN 0014-2972

Tung, K. T., Downes, M. O. \& O'Donnell, P. J. (1992). Renal biopsy in diffuse renal disease-experience with a 14-gauge automated biopsy gun. Clin Radiol, Vol. 46, No. 2, (August 1992), pp. 111-3, ISSN 0009-9260

Waldo, B. et al. (2009). The value of post-biopsy ultrasound in predicting complications after percutaneous renal biopsy of native kidneys. Nephrol Dial Transplant, Vol. 24, No. 8, (August 2009), pp. 2433-9, ISSN 1460-2385 


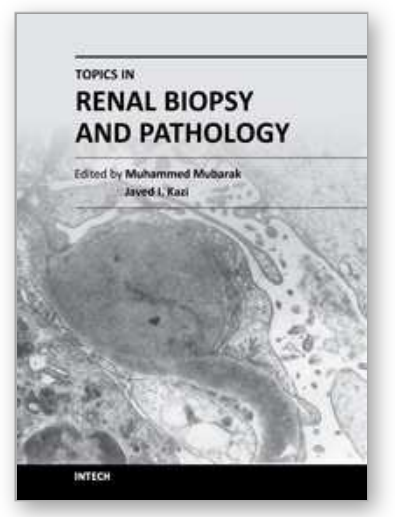

\author{
Topics in Renal Biopsy and Pathology \\ Edited by Dr. Muhammed Mubarak
}

ISBN 978-953-51-0477-3

Hard cover, 284 pages

Publisher InTech

Published online 04, April, 2012

Published in print edition April, 2012

There is no dearth of high-quality books on renal biopsy and pathology in the market. These are either single author or multi-author books, written by world authorities in their respective areas, mostly from the developed world. The vast scholarly potential of authors in the developing countries remains underutilized. Most of the books share the classical monotony of the topics or subjects covered in the book. The current book is a unique adventure in that it bears a truly international outlook and incorporates a variety of topics, which make the book a very interesting project. The authors of the present book hail not only from the developed world, but also many developing countries. The authors belong not only to US but also to Europe as well as to Pakistan and Japan. The scientific content of the book is equally varied, spanning the spectrum of technical issues of biopsy procurement, to pathological examination, to individual disease entities, renal graft pathology, pathophysiology of renal disorders, to practice guidelines.

\title{
How to reference
}

In order to correctly reference this scholarly work, feel free to copy and paste the following:

Louis-Philippe Laurin, Alain Bonnardeaux, Michel Dube and Martine Leblanc (2012). Percutaneous Renal Biopsy, Topics in Renal Biopsy and Pathology, Dr. Muhammed Mubarak (Ed.), ISBN: 978-953-51-0477-3, InTech, Available from: http://www.intechopen.com/books/topics-in-renal-biopsy-and-pathology/percutaneouskidney-biopsy

\section{INTECH}

open science | open minds

\author{
InTech Europe \\ University Campus STeP Ri \\ Slavka Krautzeka 83/A \\ 51000 Rijeka, Croatia \\ Phone: +385 (51) 770447 \\ Fax: +385 (51) 686166 \\ www.intechopen.com
}

\author{
InTech China \\ Unit 405, Office Block, Hotel Equatorial Shanghai \\ No.65, Yan An Road (West), Shanghai, 200040, China \\ 中国上海市延安西路65号上海国际贵都大饭店办公楼 405 单元 \\ Phone: +86-21-62489820 \\ Fax: +86-21-62489821
}


(C) 2012 The Author(s). Licensee IntechOpen. This is an open access article distributed under the terms of the Creative Commons Attribution 3.0 License, which permits unrestricted use, distribution, and reproduction in any medium, provided the original work is properly cited. 